\title{
EFFECT OF THE METALLIZATION TREATMENT ON THE SURFACE PROPERTIES OF POPULUS EUPHRATICA
}

\author{
Ruyuan Yang, Xiaofeng Zhang, Youfu Sun, Tingting Zhou, Quan Yuan \\ Nanjing Forestry University \\ China \\ (Received May 20I9)
}

\begin{abstract}
To improve the surface-finishing performance and enhance the protection of surface coatings, this study employed metallization treatment of fast-growing poplar through an orthogonal experiment. The poplar specimens were impregnated using a low-melting point alloy at different temperatures $\left(75^{\circ} \mathrm{C}, 85^{\circ} \mathrm{C}, 95^{\circ} \mathrm{C}\right)$, pressures $(0.5 \mathrm{MPa}, 1 \mathrm{MPa}, 1.5 \mathrm{MPa})$, and times $(0.5 \mathrm{~h}, 1 \mathrm{~h}, 2 \mathrm{~h})$ to obtain the optimum process parameters and determine the paint film adhesion of metalized poplar. The test results showed that the impregnation effect was obvious with an increase in the pressure and time. The optimum process parameters were $0.5 \mathrm{MPa}, 85^{\circ} \mathrm{C}$, and $1 \mathrm{~h}$. Contact angle of the treated wood increased, the surface free energy dropped to some extent, wetting property of tread wood decreased. Whether the treated wood or the untreated wood, film adhesion of treated wood got a higher level. After anti-aging treatment, the treated poplar still had a higher level of film adhesion.
\end{abstract}

KEYWORDS: Fast-growing poplar (Populus), metallization, contact angle, mechanical property, paint film properties.

\section{INTRODUCTION}

Poplar wood, which is widely distributed in China, grows fast, has a strong adaptability to environmental changes, and is suitable for wide applications (Zhang and Yang 2012, Kou 2006). The properties of various poplar wood species are not very different. Generally, sapwood is a pale yellow to light fawn color (Populus euphratica is light red) and heartwood is darker in color than sapwood. Diffuse-porous or semi diffuse-porous wood has many pores, and the density of air-dried wood is between $0.30 \mathrm{~kg} \cdot \mathrm{m}^{-3}$ and $0.55 \mathrm{~kg} \cdot \mathrm{m}^{-3}$. The texture of the wood is detailed and uniform, and therefore it is easy to dry and has a good processing performance (He et al. 2008, Sun and Yang 2011). However, the formed material is loose, soft, and weak with a low surface hardness; low wear resistance, low content of extractives in the heartwood, poor durability, and poor corrosion resistance, which limit the applications of poplar ( $\mathrm{Li}$ et al. 2018). 
The metallization treatment of wood is intended to improve the dimensional stability and surface finishing performance of wood-based materials, and thus enhance the protection of the surface finishing (Gobakken and Westin 2008 , Kielmann et al. 2016), reduce decay, prolong the service life, meet the demands for wood products (Jirous-Rajkovic et al. 2004, Hakkou et al. 2005), and expand the application range of fast-growing poplar.

During World War II, metalized wood was used as a bearing for ships and helicopter propellers in Germany. The density of metalized wood can reach $0.95 \mathrm{~kg} \cdot \mathrm{m}^{-3}$ to $3.83 \mathrm{~kg} \cdot \mathrm{m}^{-3}$, with a considerable increase in the hardness and wear resistance upon combining with alloys, such as $\mathrm{Sn}, \mathrm{Bi}, \mathrm{Pb}$, etc. ( $\mathrm{Si}$ 2003). Metallization is an effective way to improve the wood dimensional stability and biological durability, and is an environmentally friendly wood preservation method (Hill 2006, Yildiz and Gümüşkaya 2007, Aytin and Korkut 2016, Toker et al. 2016, Turkoglu et al. 2017, Kucuktuvek et al. 2017, Kart et al. 2019). After metallization, the properties of wood are favorable for making outdoor furniture, floor materials, various instruments for outdoor and indoor applications, and cladding for wood buildings (Homan and Jorissen 2004). Okon et al. (2018) used a low-melting point alloy to metalize Masson pine (Pinus massoniana) to study the change in its strength characteristics, contact angle, color, etc. Scanning electron microscopy was used to evaluate the effectiveness of the treatment (Okon et al. 2018). A preliminary study of metalized wood was done by Li J. and Li G. (1994) and Li (1995) by injecting molten metal or alloy into porous wood to form wood-metal composites (also called metalized wood). If the wood was compressed after impregnation with metal, metalized compact wood could be obtained ( $\mathrm{Lu}$ and Chen 2003). Wang et al. (2006) used the electroless nickel plating method to metalize wood and studied the influence of the amount of plating solution, treatment time, and temperature on the surface resistivity and electromagnetic shielding effectiveness of wood.

In this study, a pressurized impregnation method was used to metalize fast-growing poplar. The air-dried wood was impregnated using a low-melting point alloy under various temperatures, pressures, and impregnation ratios, and the density and surface impregnation area of the wood were calculated. Before and after the metallization treatment, the contact angles of distilled water on the surfaces of untreated and treated poplar specimens were measured. The surface paint film adhesion grades of all of the painted specimens that were treated and not treated with an anti-aging treatment were then evaluated.

\section{MATERIAL AND METHODS}

\section{Materials}

The experiments were performed in a laboratory at the Material Science and Engineering School of Nanjing Forestry University in Nanjing, China. During the experiment, the ambient temperature was between $26^{\circ} \mathrm{C}$ and $28^{\circ} \mathrm{C}$ and the relative humidity was between $42 \%$ and $45 \%$.

The pressure vessel used for metallization of the wood was a series of high-pressure reactors, which consisted of a reactor body and controller produced by Zhuoqun Instrument Equipment Co. Ltd. (Zhaoyuan, China). The reactor body consisted of a reaction vessel, safety device, heating furnace, etc. The section and top views of the reactor are shown in Fig. 1.

The wood used for this study was fast-growing Populus euramericana, purchased from a wood sales plant in Yibei Township of Guanyun (China). The tree age was 12 years and the diameter at breast height was approximately $350 \mathrm{~mm}$. The other characteristics included a loose tree-texture, light yellow sapwood, light brown heartwood, following the standard ISO 3131-1975 (ISO 3131 1975), an air-dry density of $0.5034 \mathrm{~kg} \cdot \mathrm{m}^{-3}$. The wet untreated poplar was cut by a bandsaw into 
quarter-sawn timber with the dimensions $950 \times 120 \times 30 \mathrm{~mm}$. The quarter-sawn poplar timber was then dried to approximately $10 \%$ of its original water content. The quarter-sawn poplar timber was planed after drying and then cut into specimens with the desired dimensions by a circular saw. The dimensions of the specimens were $20 \times 20 \times 20 \mathrm{~mm}, 30 \times 20 \times 20 \mathrm{~mm}$, and $60 \times 60 \times 6 \mathrm{~mm}$.
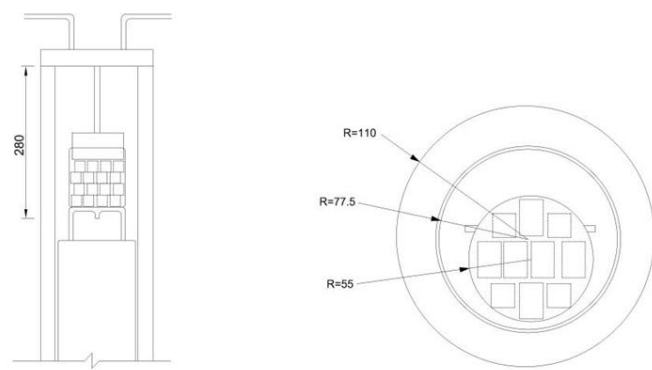

Fig. 1: Section view and top view of the reactor.

Following the standard ISO 3129-2012 (ISO 3129 2012), the minimum number of specimens required at a $\mathrm{P}$ of $5 \%$ was calculated using Eq. 1 based on a confidence level of 0.95 :

$$
\mathrm{n}_{\min }=\frac{v^{2} t^{2}}{P^{2}}
$$

where: $n_{\min }$ - the minimum number of specimens required; $v$ - the coefficient of variability of the measured properties (\%); $t$ - the reliability index, taking 1.96 as per the 0.95 confidence level; and $P$ - the test accuracy index (5\%).

The results were rounded to a single digit based on the rules of rounding off for numerical values and expression, and judgement of the limiting values (GB/T 8170 2008). Based on the tree species, the required specimen characteristics for testing the related properties are shown in Tab. 1 .

Tab. 1: Wood samples.

\begin{tabular}{|l|c|c|c|}
\hline \multicolumn{1}{|c|}{ Wood property } & $\mathrm{CV}(\%)$ & $n_{\min }$ & Dimensions $(\mathrm{mm})$ \\
\hline Density & 10 & 15 & $30 \times 20 \times 20$ \\
\hline Shrinkage (linear) & 28 & 20 & $20 \times 20 \times 20$ \\
\hline $\begin{array}{l}\text { Compression strength } \\
\text { parallel to the grain }\end{array}$ & 13 & 15 & $30 \times 20 \times 20$ \\
\hline
\end{tabular}

$$
\mathrm{CV} \text { - coefficient of variation. }
$$

The low-melting point alloy used for impregnation was provided by Pujiang Alloy Materials Co., Ltd. (Nanjing, China). The main components were $\mathrm{Sn}, \mathrm{Bi}$, and $\mathrm{Pb}$, the density was approximately $39.6 \mathrm{~kg} \cdot \mathrm{m}^{-3}$, and the melting point was approximately $70^{\circ} \mathrm{C}$. This alloy had a silver white color while solid and bright silver white color after melting. The alloy existed as a solid at room temperature, and exhibited the desired strength, hardness, corrosion resistance, and other properties. Two kilograms of the alloy when placed in $75^{\circ} \mathrm{C}$ water began to melt after $40 \mathrm{~min}$ and melted completely in approximately $4 \mathrm{~h}$; in $85^{\circ} \mathrm{C}$ water, the alloy melted completely in $0.5 \mathrm{~h}$; and in $95^{\circ} \mathrm{C}$ water, the alloy melted completely in $10 \mathrm{~min}$. The molten alloy did not solidify at a temperature of $75^{\circ} \mathrm{C}$ to $95^{\circ} \mathrm{C}$. In air, a gray oxide film formed on the surface of the molten metal alloy. At higher temperatures, this film oxidized easily. 
A static drop contact angle or interfacial tension measuring instrument (JC2000A, Zhongchen Digital Technology Equipment Co. Ltd., Shanghai, China) was used for wettability testing of the surface of the impregnated wood. The instrument had DH-CG400 image card driving software (China Daheng Co. Ltd., Beijing, China). The main interface and other supporting components included a microsyringe (1-ml syringe), 3D platform, dimming knob, and focusing control panel. The test material used was fast-growing untreated and metal-impregnated poplar specimens with the dimensions 20 (radial) $\times 20$ (tangential) $\times 30 \mathrm{~mm}$ (length) The specimen samples were prepared using three technical conditions, which were named Group B (0.5 MPa for $1 \mathrm{~h}$ at $85^{\circ} \mathrm{C}$ and a density of $\left.3.19 \mathrm{~kg} \cdot \mathrm{m}^{-3}\right)$; Group $\mathrm{C}\left(0.5 \mathrm{MPa}\right.$ for $2 \mathrm{~h}$ at $95^{\circ} \mathrm{C}$ and a density of $\left.3.08 \mathrm{~kg} \cdot \mathrm{m}^{-3}\right)$; and Group $\mathrm{G}\left(1.5 \mathrm{MPa}\right.$ for $2 \mathrm{~h}$ at $75^{\circ} \mathrm{C}$ and a density of $\left.3.73 \mathrm{~kg} \cdot \mathrm{m}^{-3}\right)$. The surfaces of all of the specimens were polished with \#320 abrasive paper before impregnation.

For paint film adhesion testing of the impregnated wood, a QFH cross-cut tester (Jingkelian Material Testing Machine Co. Ltd., Tianjin, China), HSRO25 artificial climate box with ultraviolet lamp (Nanjing Experimental Instrument Factory, Nanjing, China), wool brush, plastic bucket, and electronic scale (with a precision of $0.01 \mathrm{~g}$ ) were used. The test materials included alkyd varnish and phenolic enamel (Changjiang Paint Company Ltd., Jiangsu, China), a two-component polyurethane resin varnish (Taicang Lugong Special Coating Factory, Suzhou, China), and poplar specimens $(60 \times 60 \times 6 \mathrm{~mm})$ that underwent the metallization treatment.

\section{Methods}

\section{Impregnating metallization treatment of the wood}

The reactor setup for the metal impregnation of the poplar specimen is shown in Fig. 1. The stainless-steel reactors, which contained the low-melting point alloy and specimens, were kept in an autoclave. The liner support heating jacket set by the reactor continuously transferred heat to the reactor, and the heat was transmitted to the stainless-steel container using water as the medium. Pressure was applied when the set temperature was reached.

Poplar wood is a diffuse-porous or semi diffuse-porous wood with many holes and has a loose texture; thus, it exhibits a good wettability. In this experiment, the poplar specimens were impregnated and metalized by the pressure impregnation method according to the L9 (34) orthogonal table. The pressure, temperature, and time were selected as influencing factors on the impregnation effect. The temperature and time had three levels, and the pressure had five levels. A total of 11 experiments were conducted. The factor levels are shown in Tab. 2.

Tab. 2: Levels of the factors.

\begin{tabular}{|c|c|c|c|}
\hline \multirow{2}{*}{ Level } & \multicolumn{3}{|c|}{ Factor } \\
\cline { 2 - 4 } & Pressure $(\mathrm{MPa})$ & Temperature $\left({ }^{\circ} \mathrm{C}\right)$ & Time $(\mathrm{h})$ \\
\hline 1 & 0.5 & 75 & 0.5 \\
\hline 2 & 1 & 85 & 1 \\
\hline 3 & 1.5 & 95 & 2 \\
\hline 4 & 0.1 & - & - \\
\hline 5 & 0.3 & - & - \\
\hline
\end{tabular}

Surface wettability test of the impregnated wood

Surface wettability of wood-based materials plays an important role in the coating of wood surfaces and the movement of moisture in wood. The surface wettability values indicate the effect of wetting, spreading, and adhesion of various liquids or reagents (water, adhesive, oxidizer, crosslinker, water repellent, dyeing agent, paint, and treatment solutions for various 
modifications) on the surface (Teng 2009). The contact angle between wood and liquids is an important parameter to measure the diffusion of water-soluble paint on wood surfaces.

Various methods for determining the contact angle include the light point reflection, tilting plate, sessile drop, drooping, and capillary rise methods. In general, the contact angle of wood is often determined by the sessile drop and capillary rise methods ( $\mathrm{Gu}$ 1999). The sessile drop method was used in this experiment, with distilled water as the testing liquid. A JC2000A static drop contact angle or interfacial tension measuring instrument (Zhongchen Digital Technology Equipment Co., Ltd., Shanghai, China) was used and the average value for each test block was taken. The measurement was divided into two parts, which were the collection of specimen images in the wet state and measurement of the contact angle.

\section{Paint film adhesion test of the impregnated wood}

The paint film adhesion refers to the adhesion property between a paint film and surface of a coated substrate. It is one of the important indices to measure the performance of paint. The untreated and treated poplar wood specimens were first polished using \#180 coarse and \#320 fine abrasive paper to obtain a relatively smooth surface. The specimens were not treated with putty in the experiment. All of the specimens were painted twice, where the second coat was applied after the first coat was nearly dry. The painted specimens are shown in Fig. 2. The paint film adhesion of the painted specimens was measured after two weeks of air drying.

The paint film adhesion test was performed as per the standard method BS 3962-6-1980 (BS 3962-6 1980). First, the surfaces of the untreated and treated wood specimens were coated with the alkyd varnish, phenolic enamel, and polyurethane resin varnish for a total of six specimens. The specimen numbers are shown in Tab. 3 .

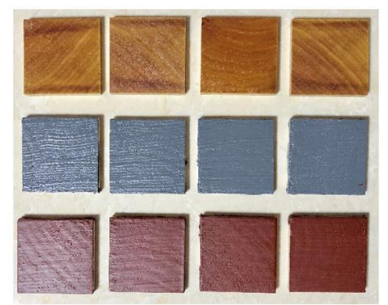

Fig. 2: Painted specimens.

Tab. 3: Specimen numbers for the adhesion test.

\begin{tabular}{|l|c|c|c|}
\hline Impregnation process & Alkyd varnish & Phenolic enamel & Polyurethane resin varnish \\
\hline Untreated & 1 & 2 & 3 \\
\hline Treated & 4 & 5 & 6 \\
\hline
\end{tabular}

Second, the center of each specimen was used as the test area to measure the thickness of the two-point paint films and the arithmetic mean value was obtained. Third, two groups of rectangular marks were cut on the surface of the paint films, each of which included 11 parallel cuts with a length of $35 \mathrm{~mm}$ and spacing of $2 \mathrm{~mm}$. All of the cuts penetrated into the surface of the base material, and the cut marks were angled approximately $45^{\circ}$ in the direction of the wood grain. Fourth, the scraps were dusted with a paint brush and a rubber paste was pressed by hand onto the cut parts of the test area. Finally, the rubber paste was exposed abruptly in the diagonal direction to carefully check the damage of the paint film with a magnifying glass under an observation lamp. 
After the adhesion test, anti-aging testing was done. For this purpose, the surfaces of the untreated and treated wood were coated with alkyd varnish, phenolic enamel, and polyurethane resin varnish for a total of six specimens. The specimen numbers are shown in Tab. 4 .

Tab. 4: Specimen numbers for the anti-aging test.

\begin{tabular}{|l|c|c|c|}
\hline Impregnation process & Alkyd varnish & Phenolic enamel & Polyurethane resin varnish \\
\hline Untreated & 7 & 8 & 9 \\
\hline Treated & 10 & 11 & 12 \\
\hline
\end{tabular}

The specimens were installed in an aging tester (HSR025, Nanjing Test Instrument Factory, Nanjing, China) at $45^{\circ} \mathrm{C} \pm 5^{\circ} \mathrm{C}$ with a relative humidity of $65 \%$ to $90 \%$. The specimens were sprayed with a water jet once an hour with a spray time of $3 \mathrm{~min}$. The specimens were removed after $72 \mathrm{~h}$ in the aging tester, and then wiped and cleaned with clean absorbent gauze containing a small amount of alcohol. Finally, the cracks on the surfaces of the specimens were observed under natural light. The measured value of the paint film adhesion was compared with the results before the aging test.

\section{RESULTS AND DISCUSSION}

\section{Impregnating metallization treatment of the wood}

Following the L9 $\left(3^{4}\right)$ orthogonal table, 11 groups of experiments were performed. The factors studied included the pressure, temperature, and time. The pressure values were $0.1 \mathrm{MPa}$, $0.3 \mathrm{MPa}, 0.5 \mathrm{MPa}, 1 \mathrm{MPa}$, and $1.5 \mathrm{MPa}$; the temperatures were $75^{\circ} \mathrm{C}, 85^{\circ} \mathrm{C}$, and $95^{\circ} \mathrm{C}$; and the time intervals were $0.5 \mathrm{~h}, 1 \mathrm{~h}$, and $2 \mathrm{~h}$. The impregnation effect on the poplar wood under the various experimental conditions is shown in Tab. 5 .

Tab. 5: Effect of impregnation with different conditions.

\begin{tabular}{|c|c|c|c|c|c|}
\hline No. & Pressure $(\mathrm{MPa})$ & Temperature $\left({ }^{\circ} \mathrm{C}\right)$ & Time $(\mathrm{h})$ & $\rho\left(\mathrm{kg}^{-3}\right)$ & $\beta(\%)$ \\
\hline Untreated & - & - & - & 0.5034 & 100 \\
\hline A & 0.5 & 75 & 0.5 & 2.6600 & 100 \\
\hline B & 0.5 & 85 & 1 & 3.1885 & 100 \\
\hline C & 0.5 & 95 & 2 & 3.0827 & 100 \\
\hline D & 1 & 75 & 1 & 3.3624 & 100 \\
\hline E & 1 & 85 & 2 & 3.4471 & 100 \\
\hline F & 1 & 95 & 0.5 & 2.8933 & 100 \\
\hline G & 1.5 & 75 & 2 & 3.7269 & 100 \\
\hline H & 1.5 & 85 & 0.5 & 3.3830 & 100 \\
\hline I & 1.5 & 95 & 1 & 4.0485 & 100 \\
\hline J & 0.1 & 85 & 0.5 & 2.2231 & 82 \\
\hline K & 0.3 & 85 & 0.5 & 2.2811 & 90 \\
\hline
\end{tabular}

$\rho$ - density, $\beta$-surface impregnation rate.

The surface impregnation rate was calculated by the number grid method. The area ratio of the surface layer impregnated is the result measured by observing the impregnated specimen on the macro level. The place where the metal was impregnated on the surface of the specimen 
presents the metal color, which was different from the place where the specimen was not impregnated. A transparent sheet with a $2 \times 2 \mathrm{~mm}$ grid was placed on the surface of the specimen, and the number of grids showing the metal color was calculated. The part less than one grid shall be roughly calculated according to the proportion. The impregnation surface area ratio is expressed as follows:

$$
\beta=\frac{n_{1}}{n_{2}} \times 100 \%
$$

where: $\quad n_{1}$ - the number of grids showing the metal color,

$n_{2}$ - the number of grids occupied by the specimen.

Tab. 5 revealed that the density increased considerably after metallization under the various conditions, and was approximately four to eight times more than that before the treatment. The main reason for this result was attributed to the larger density of the low-melting point alloy. When the poplar specimens were immersed in the alloy, the density of the specimens increased. When the pressure was greater than $0.5 \mathrm{MPa}$, the surface impregnation of the specimen was good, which showed that under the orthogonal experimental design conditions, the impregnation effect was obvious and a favorable impregnation surface was obtained. However, when the pressure was less than $0.5 \mathrm{MPa}$, impregnation of the poplar specimen was not sufficient and hence the surface impregnation effect of the specimen was not good.

Variance and range analyses of the impregnation test results were analyzed by using Orthogonal Design Assistant Software. The results were as follows. The $F$ ratios of the pressure and time were greater than 19 and the $F$ ratio of the pressure was greater than that of the time (Tab. 6), which indicated that the pressure and time have a significant influence on the impregnation effect. The impact of the pressure on impregnation was greater than that of the time. Because the $F$ ratio of the temperature was less than 19 , the temperature range of the orthogonal design had no obvious effect on the impregnation of the specimen.

Tab. 6: Variance analysis of the effect of impregnation.

\begin{tabular}{|l|c|c|c|c|c|}
\hline \multicolumn{1}{|c|}{ Factor } & $\begin{array}{c}\text { Square of } \\
\text { deviance }\end{array}$ & $\begin{array}{c}\text { Degree of } \\
\text { freedom }\end{array}$ & F ratio & $\begin{array}{c}\text { Critical } \\
\text { F-values }\end{array}$ & Significance \\
\hline Pressure $(\mathrm{MPa})$ & 0.853 & 2 & 34.120 & 19.000 & $*$ \\
\hline Temperature $\left({ }^{\circ} \mathrm{C}\right)$ & 0.016 & 2 & 0.640 & 19.000 & - \\
\hline Time $(\mathrm{h})$ & 0.514 & 2 & 20.560 & 19.000 & $*$ \\
\hline Error & 0.03 & 2 & - & - & - \\
\hline
\end{tabular}

This conclusion was reached because of the differences in the ranges for each factor in Tab. 7 . For the factors in the orthogonal experiment, the density ranges of the metalized poplar specimen with the pressure and time were large, which indicated that the pressure and time significantly influenced the impregnation effect.

Tab. 7: Range analysis of the effect of impregnation.

\begin{tabular}{|l|c|c|c|c|c|c|c|c|c|}
\hline \multicolumn{1}{|c|}{ Factor } & \multicolumn{3}{|c|}{ Pressure $(\mathrm{MPa})$} & \multicolumn{3}{c|}{ Temperature $\left({ }^{\circ} \mathrm{C}\right)$} & \multicolumn{3}{c|}{ Time $(\mathrm{h})$} \\
\hline Level & 0.5 & 1 & 1.5 & 75 & 85 & 95 & 0.5 & 1 & 2 \\
\hline Average & 2.977 & 3.234 & 3.719 & 3.250 & 3.340 & 3.341 & 2.979 & 3.533 & 3.419 \\
\hline Range & \multicolumn{3}{|c|}{0.742} & \multicolumn{3}{c|}{0.091} & \multicolumn{3}{c|}{0.554} \\
\hline
\end{tabular}


However, the density range of the metalized poplar specimen with the temperature was small, which indicated that the effect of the temperature on the impregnation effect was not significant. The specific analysis of the various factors is shown in Fig. 3.

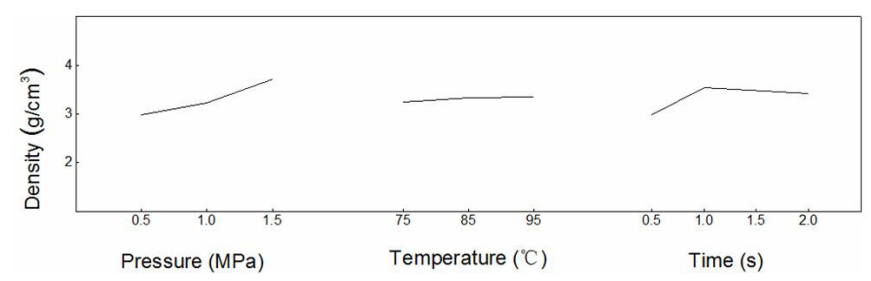

Fig. 3: Visual analysis of the effect of impregnation.

\section{Pressure}

The influence of the pressure on the impregnation was noticeable. As the pressure increased from $0.5 \mathrm{MPa}$ to $2 \mathrm{MPa}$, the density of the specimen obviously increased and the impregnation was gradually improved, as is shown in Fig. 3. To further investigate the effect of the pressure, experiments 10 and 11 were done. It was found that the specimen can also be impregnated under a pressure of $0.1 \mathrm{MPa}$ and $0.3 \mathrm{MPa}$ at $85^{\circ} \mathrm{C}$ and a time of $0.5 \mathrm{~h}$, but the impregnation effect was not as good as that of the other test groups. The surface impregnation effect was reduced because of inadequate impregnation. Therefore, a pressure of $0.5 \mathrm{MPa}$ was chosen as the best process parameter for a good impregnated surface.

\section{Temperature}

The temperature range of $75^{\circ} \mathrm{C}$ to $100^{\circ} \mathrm{C}$ for the orthogonal experiment guaranteed the alloy was in a molten state and avoided a negative influence on the properties of the molten alloy and poplar specimens because of the high temperature. However, the temperature range had little effect on the impregnation of the specimen, as is shown in Fig. 3. The density of the treated specimen was relatively unchanged. To ensure that the alloy was in a molten state and the energy loss was reduced, a temperature of $85^{\circ} \mathrm{C}$ was chosen as the best process parameter.

Time

Under pressure, when the impregnation time was longer, the sample exhibited a better impregnation effect. For the impregnated samples, a time of $2 \mathrm{~h}$ was able to attain a good impregnation effect. Fig. 3 shows that the impregnation effect improved with an increase in the time; after $1 \mathrm{~h}$, the impregnation effect instead decreased, which may have been because of the comprehensive function of the other factors. Therefore, a time of $1 \mathrm{~h}$ was selected as the optimum process parameter.

\section{Surface wetting experiments of the impregnated materials}

The contact angle changes of the radial and tangential sections of the untreated and treated wood using distilled water with time are shown in Tab. 8 and Tab. 9 and Fig. 4. The contact angle measurements were done through the collection of pictures of the morphological change of the static liquid drop on the sample surface and angle measurements from the pictures. Because of the fast changes in the contact angle on the radial section of the untreated wood, the measurement was done in 2-s intervals, while for the tangential section, it was done in 1-s intervals. The contact angle for the treated wood with distilled water changed relatively slowly, so the contact angle was measured with a 12 -s interval. 
Vol. 65 (3): 2020

Tab. 8: Change in the contact angle with time for the untreated specimens.

\begin{tabular}{|l|c|c|c|c|c|c|c|c|}
\hline \multicolumn{1}{|c|}{ Time (s) } & 2 & 4 & 6 & 8 & 10 & 12 & 14 & 16 \\
\hline $\begin{array}{l}\text { Contact angle of the radial } \\
\text { section }\left(^{\circ}\right)\end{array}$ & 56.83 & 44.42 & 36.08 & 31.50 & 27.50 & 23.75 & 19.08 & 15.58 \\
\hline Time (s) & 1 & 2 & 3 & 4 & 5 & 6 & 7 & 8 \\
\hline $\begin{array}{l}\text { Contact angle of the tangential } \\
\text { section }\left(^{\circ}\right)\end{array}$ & 62.75 & 45.75 & 36.00 & 28.25 & 22.25 & 17.50 & 14.75 & 11.75 \\
\hline
\end{tabular}

Tab. 9: Change in the contact angle with time for the treated specimens.

\begin{tabular}{|c|c|c|c|c|c|c|}
\hline \multirow[b]{2}{*}{ Time (s) } & \multicolumn{6}{|c|}{ Contact angle $\left({ }^{\circ}\right)$} \\
\hline & $\begin{array}{c}\text { Radial } \\
\text { section } \\
\text { (Group B) }\end{array}$ & $\begin{array}{c}\text { Tangential } \\
\text { section } \\
\text { (Group B) }\end{array}$ & $\begin{array}{c}\text { Radial } \\
\text { section } \\
\text { (Group C) }\end{array}$ & $\begin{array}{l}\text { Tangential } \\
\text { section } \\
\text { (Group C) }\end{array}$ & $\begin{array}{c}\text { Radial } \\
\text { section } \\
\text { (Group G) }\end{array}$ & $\begin{array}{c}\text { Tangential } \\
\text { section } \\
\text { (Group G) }\end{array}$ \\
\hline 12 & 73.10 & 88.67 & 71.33 & 74.50 & 97.50 & 95.00 \\
\hline 24 & 62.30 & 78.33 & 62.67 & 65.33 & 84.67 & 63.17 \\
\hline 36 & 59.30 & 76.00 & 60.67 & 60.50 & 78.83 & 56.17 \\
\hline 48 & 57.00 & 73.75 & 58.00 & 56.83 & 76.17 & 52.33 \\
\hline 60 & 54.30 & 70.83 & 54.83 & 53.17 & 74.00 & 47.33 \\
\hline 72 & 51.20 & 68.67 & 52.17 & 49.50 & 70.83 & 41.17 \\
\hline 84 & 48.50 & 65.83 & 49.17 & 45.33 & 68.50 & 35.33 \\
\hline 96 & 45.50 & 63.17 & 46.67 & 41.17 & 66.67 & 28.00 \\
\hline 108 & 42.90 & 60.00 & 44.00 & 36.83 & 62.67 & 20.67 \\
\hline 120 & 40.30 & 56.33 & 41.33 & 31.67 & 59.50 & 9.67 \\
\hline
\end{tabular}

Because of some definite variations in the size selected for the initial distilled water hanging drop, the initial wetting angles were different. Hence, for those experiments, the contact angle and its change rate were taken as the wetting judgment standard and were used to evaluate the wettability of the untreated and treated wood specimens in the combined analysis.

Figs. 4a to $4 \mathrm{f}$ show that the contact angle changed with distilled water had a good exponential regression relationship with the time for both the untreated and treated poplar specimens. For the untreated poplar specimens, the wettability in the tangential section was larger than that in the radial section, and the rate of contact angle change for the tangential section was larger than that for the radial section. However, for the treated samples, the rates of contact angle change for the radial and tangential sections with distilled water tended to be the same (Figs. $4 \mathrm{a}$ to $4 \mathrm{~d}$ ). After insufficient alloy impregnation of the samples, the rate of contact angle change for the tangential section was larger than for the radial section (Fig. 4d) because the tangential void ratio of the untreated poplar was larger than the radial porosity. When the sample was not completely impregnated by the metal, the radial and tangential void ratios tended to be the same, and showed a similar change trend for the wetting angle. However, when the sample was completely impregnated, its absorption of distilled water relied on the hydrophilic xylem, where the tangential wettability was larger than the radial wettability. The change rate for the tangential section with distilled water was larger than that for the radial section. 


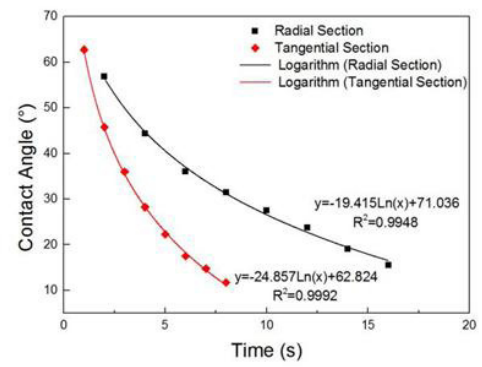

(a) Untreated

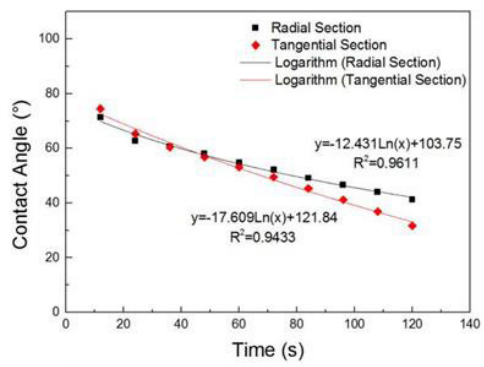

(c) Group C

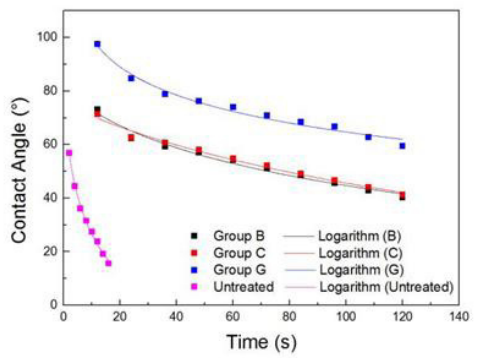

(e) Radial Section

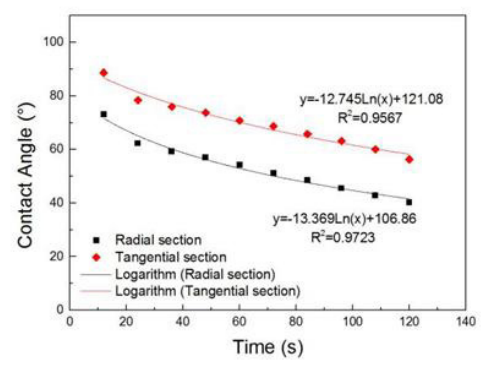

(b) Group B

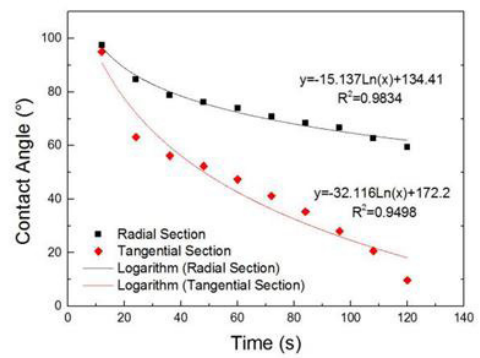

(d) Group D

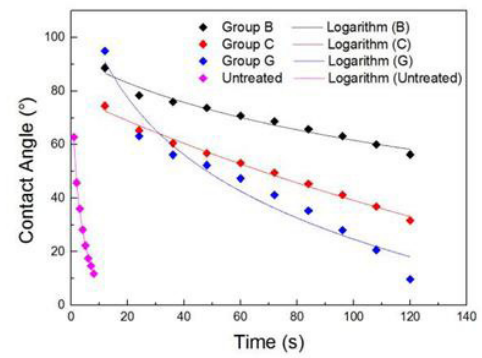

(f) Tangential Section

Fig. 4: Change in the contact angle with time for: (a) the untreated specimens, (b) Group B; (c) Group C; (d) Group G; (e) radial section, and (f) tangential section.

Fig. 4e shows that the wettability of the radial section of the treated poplar sample was smaller than that of the untreated wood. Also, as the wetting effect improved, the radial section had a poorer wettability. Group $G$ displayed the best impregnation effect with a weakened wettability in the radial section. Groups B and C exhibited equivalent impregnation effects, with equivalent section wetting properties.

Fig. $4 \mathrm{f}$ shows that the wettability of the radial section of the treated wood sample was smaller than that of the untreated wood. Moreover, as the wetting effect improved, the wettability in the radial section weakened. Groups B and $\mathrm{C}$ had equivalent impregnation effects, with an equivalent wettability for the tangential sections. Group $\mathrm{G}$ had the best impregnation effect and theoretically the poorest wettability because of the roughness of the sample surface treatment. 


\section{Coating adhesion test after painting the metalized poplar surface}

The experimental results are shown in Tab. 10 and Tab. 11:

Tab. 10: Grading standards for the film adhesion test.

\begin{tabular}{|c|l|}
\hline Grade & \multicolumn{1}{c|}{ Description } \\
\hline 1 & The cut marks were smooth, no paint film peeling. \\
\hline 2 & $\begin{array}{l}\text { There was paint film flaking at the intersection of the cut, and there was a small } \\
\text { amount of intermittent peeling of the paint film. }\end{array}$ \\
\hline 3 & There was intermittent or continuous peeling of the paint film along the cut marks. \\
\hline 4 & $\begin{array}{l}\text { In under } 50 \% \text { of the rectangular cut marks, the paint film had large pieces of debris } \\
\text { or it completely peeled off along the cut marks. }\end{array}$ \\
\hline 5 & $\begin{array}{l}\text { In more than } 50 \% \text { of the rectangular cut marks, the paint film had large pieces of } \\
\text { debris or completely peeled off along the cut marks. }\end{array}$ \\
\hline
\end{tabular}

Tab. 11: Results of the paint film adhesion test.

\begin{tabular}{|c|c|c|}
\hline No. & $\begin{array}{c}\text { Grade of paint } \\
\text { film adhesion }\end{array}$ & $\begin{array}{c}\text { Film thickness } \\
(\mathrm{mm})\end{array}$ \\
\hline A & 1 & 0.719 \\
\hline B & 3 & 0.156 \\
\hline C & 1 & 0.146 \\
\hline D & 1 & 0.153 \\
\hline E & 2 & 0.147 \\
\hline F & 2 & 0.145 \\
\hline G & 2 & 0.158 \\
\hline H & 5 & 0.144 \\
\hline I & 2 & 0.142 \\
\hline J & 1 & 0.169 \\
\hline K & 3 & 0.158 \\
\hline L & 1 & 0.149 \\
\hline
\end{tabular}

The analysis of the data indicated the following:

At room temperature and ventilation conditions, the polyurethane resin varnish had the shortest film formation time. In contrast, the film formation time of the alkyd varnish was longest, at one week. The hardening agent used in the polyurethane resin varnish accelerated the solidification process.

All of the samples used in the experiment had no putting, but were sanded. Therefore, the metalized poplar samples had a more even surface and provided a more even paint film after sanding. The film thickness was thinner than that of the untreated wood. Because of metallization of the poplar specimens, the vessels and wood fibrocystic cavities were impregnated with the alloy, which decreased the void ratio of the surface.

Upon crosswise comparison of the untreated poplar and metalized wood, the alkyd varnish, phenolic enamel, and polyurethane resin varnish all exhibited nearly the same film adhering ability. Upon longitudinal comparison, the film adhering ability was larger for the metalized poplar with alkyd varnish, phenolic enamel, and polyurethane resin varnish than for the untreated poplar, This results similar to that of Yu et al. (2007). 


\section{CONCLUSIONS}

The main conclusions derived from this study are summarized below:

1. Among the factors studied for the impregnation effect, the pressure and time significantly affected the metallization process, and the temperature effect was insignificant. The impregnation effect obviously increased with an increasing pressure and time. The optimum pressure, time, and temperature were determined to be $0.5 \mathrm{MPa}, 85^{\circ} \mathrm{C}$, and $1 \mathrm{~h}$, respectively.

2. For both the untreated and treated poplar, the contact angle change with distilled water exhibited a good exponential regression relationship with time; as the impregnation effect improved, the wettability weakened.

3. Compared with the untreated wood, the film adhering capacity of the metalized poplar improved considerably. After the anti-aging experiment, the metalized poplar samples showed a relatively high film adhering capacity.

\section{ACKNOWLEDGMENTS}

This research is supported by a project funded by the national first-class disciplines (PNFD), and the priority academic program development of Jiangsu Higher Education Institutions (PAPD). Any research results expressed in this paper are those of the writer(s) and do not necessarily reflect the views of the foundations. We declare that we do not have any commercial or associative interests, which represent a conflict of interest in connection with the current study.

\section{REFERENCES}

1. Aytin, A., Korkut, S., 2016: Effect of thermal treatment on the swelling and surface roughness of common alder and Wych elm wood. Journal of Forestry Research 27(1): 225-229.

2. BS 3962-6, 1980: Methods of test for finishes for wooden furniture. Assessment of resistance to mechanical damage.

3. GB/T 8170-2008, 2008: Rules of rounding off for numerical values and expression and judgement of limiting values.

4. Gobakken, L.R., Westin, M., 2008: Surface mould growth on five modified wood substrates coated with three different coating systems when exposed outdoors. International Biodeterioration and Biodegradation 62(4): 397-402.

5. Gu, J., 1999: Adhesives and coatings. China Forestry Publishing House, Beijing, China, Pp 33-34.

6. Hakkou, M., Pétrissans, M., Zoulalian, A., Gérardin, P., 2005: Investigation of wood wettability changes during heat treatment on the basis of chemical analysis. Polymer Degradation and Stability 89(1): 1-5.

7. He, M.J., Lam, F., Yang, J., Zhang, S.D. 2008: Wood structural design. Beijing, China Construction Industry Press. 317 pp.

8. Hill, C.A.S., 2006: Wood modification - chemical, thermal and other processes, John Wiley and Sons Ltd., Chichester, England, 260 pp.

9. Homan, W.J., Jorissen, A.J.M., 2004: Wood modification developments. Heron 49(4): 361-368. 
10. ISO 3129, 2012: Wood. Sampling methods and general requirements for physical and mechanical tests.

11. ISO 3131, 1975: Wood. Determination of density for physical and mechanical tests.

12. Jirous-Rajkovic, V., Bogner, A., Radovan, D., 2004: The efficiency of various treatments in protecting wood surfaces against weathering. Surface Coatings International Part B: Coatings Transactions 87(1): 15-19.

13. Kart, S., Baysal, E., Kucuktuvek, M., Turkoglu, T., Toker,H., Altay, C., Cibo, C., Peker, H., 2019: Some surface characteristics of varnished thermowood after weathering. Wood Research 64(1): 35-48.

14. Kielmann, B.C., Militz, H., Mai, C., 2016: The effect of combined melamine resin coloring agent modification on water related properties of beech wood. Wood Research 61(1): 1-12.

15. Kou, W.Z., 2006: China's poplar industry has entered a harmonious development road. China Forestry Industry 11: 14-16.

16. Kucuktuvek, M., Baysal, E., Turkoglu, T., Peker, H., Gunduz, A., Toker, H. 2017: Surface characteristics of Scots pine wood heated at high temperatures after weathering. Wood Research 62(6): 905-918.

17. Li, J., 1995: Wood composites for the 21st century. World Forestry Research (3): 34-40.

18. Li, J., Li, G., 1994: Metallic wood. Chinese Wood (6): 19-20.

19. Li, L.F., Yu, L.P., Wu, Z.G., 2018: Delignification of poplar wood with lactic acid-based deep eutectic solvents. Wood Research 64(3): 499-514.

20. Lu, C., Chen, X., 2003: Research progress in preparation of novel composite materials using wood mesoporous structure. Polymer Materials Science \& Engineering 19(6): 32-36.

21. Okon, K.E., Lin, F., Chen, Y., Huang, B., 2018: Tin-based metal bath heat treatment: An efficient and recyclable green approach for Pinus massoniana wood modification. Journal of Forestry Research 29(6): 1807-1814.

22. Si, N., 2003: Introduction of several kinds of wood and inorganic nonmetal composite materials. Building Materials Industry of Information (6): 55-56.

23. Sun, Y.F., Yang, X.J., 2011: On the development prospect of Chinese wood structural architecture. Building Materials Decoration 6, 22-26.

24. Teng, X., 2009: Surface physicochemistry. Chemical Industry Press, Beijing, China, Pp 47-53.

25. Toker, H., Baysal, E., Turkoglu, T., Kart, S., Sen, F., Peker, H. 2016: Surface characteristics of oriental beech and scots pine woods heat-treated above $200^{\circ} \mathrm{C}$. Wood Research 61(1): 43-54.

26. Turkoglu, T., Kabasakal, Y., Baysal, E., Gunduz, A., Kucuktuvek, M., Bayraktar, D.K., Toker, H., Peker, H., 2017: Surface characteristics of heated and varnished Oriental beech after accelerated weathering. Wood Research 62(6): 961-972.

27. Wang, L., Li, J., Liu, Y., 2006: Preparation of electromagnetic shielding wood-metal composite by electroless nickel plating. Journal of Forestry Research 17(1): 53-56.

28. Yildiz, S., Gümüşkaya, E., 2007: The effects of thermal modification on crystalline structure of cellulose in soft and hardwood. Building and Environment 42(1): 62-67.

29. Yu, H.P., Liu, Y.X., Luo, G.H., 2007: The change rule of visual physical quantity of transparent polyurethane coated wood. Journal of building materials (04): 89-94.

30. Zhang, D., Yang, L., 2012: Research progress in modified fast growing poplar wood. Forestry Machinery and Woodworking Equipment 40(3): 16-20. 
Ruyuan Yang, Xiaofeng Zhang, Youfu Sun*, Tingting Zhou, Quan Yuan

Nanjing Forestry University

College of Materials Science and Engineering

NANJING

China

*Corresponding author: yfsun@njfu.edu.cn 